\title{
GOVERNANÇA HÍDRICA E CONFLITOS NA RESERVA EXTRATIVISTA MARINHA BAIA DE IGUAPE
}

\author{
Alexandre de Oliveira e Aguiar \\ Doutor em Saúde Pública \\ Universidade Nove de Julho - UNINOVE São Paulo - SP - Brasil \\ alexandre@aguiar.eng.br https://orcid.org/0000-0003-3413-064X

Airton Cardoso Cançado
Doutor em Administração
Universidade Federal do Tocantins Palmas - TO - Brasil
airtoncardoso@yahoo.com.br http://orcid.org/0000-0003-4698-1804

\section{RESUMO}

A Reserva Extrativista Marinha Baia de Iguape fica no Nordeste do Brasil, na zona estuarina do Rio Paraguaçu. A gestão da Reserva envolve um conflito relacionado ao uso dos recursos hídricos a montante, com queda da vazão de água e diminuição dos estoques de recursos pesqueiros. Este trabalho tem como objetivo discutir os conflitos de uso, as visões dos atores e as causas do conflito. $\mathrm{O}$ trabalho foi realizado com base em documentos e em observação direta. Constata-se que o conflito surge de restrições de engenharia da barragem, que não permitem o controle ideal da vazão, que, para serem resolvidos, demandariam investimentos. A governança atual não tem sido capaz de produzir uma solução de consenso quanto ao modo de operar a barragem que atenda tanto à necessidade dos usuários a montante quanto aos de jusante. Não se nota, na postura dos atores, a presença do interesse bem compreendido, uma vez que não apresentam uma visão de compatibilidade entre os interesses individuais de curto prazo e os interesses coletivos de longo prazo. Entre as causas do problema, parece estar a legislação de recursos hídricos, que considera a área estuarina como elemento externo à bacia hidrográfica, fragmentando o sistema de governança $\mathrm{e}$ dificulta atingir uma solução de consenso.

Palavras-chave: Gestão de conflitos. Interesse bem compreendido. Pesca. Recursos hídricos.

Reserva extrativista.

\section{WATER RESOURCES GOVERNANCE AND CONFLICTS IN THE BAHIA DE IGUAPE MARINE EXTRACTIVE RESERVE}

\section{ABSTRACT}

The Baia de Iguape Marine Extractive Reserve is located in northeastern Brazil, in the the Paraguaçu River's estuarine zone. Its management involves a conflict related to the use of water resources upstream, with a drop in water flow and a decrease in fishing resource stocks. This paper aims to discuss the conflicts of use, the views of the actors and the causes of the conflict. The work was carried out based on documents and direct observation. It is observed that the conflict arises from the dam's engineering restrictions, which do not allow the optimal control of the water flow and that would require investments. Current governance has not been able to produce a consensus solution as to how to operate the dam meeting both the needs of upstream and downstream users. It is not noticeable, in the stakeholders' attitude, the presence of well understood interest, since they do not seem to see compatibility between individual short-term interests and long-term collective interests. Among the causes of the problem there seems to be the water resources legislation, which considers the estuarine area as an external element to the hydrographic basin, thus fragmenting the governance system and making it difficult to reach a consensus solution.

Key words: Conflict management. Extractive reserve. Fishing. Water resources. Well understood interest.

Data da submissão: $01 / 06 / 2020$

Data de aceite: $01 / 05 / 2021$ 


\section{INTRODUÇÃO}

A conservação da biodiversidade é uma questão importante que, além de preservar a beleza das paisagens, visa preservar também serviços ecossistêmicos prestados pela natureza, vários deles de valor econômico.

No Brasil, um dos instrumentos de política pública importantes para a conservação da biodiversidade é o estabelecimento de unidades de conservação. Uma delas é a Reserva Extrativista Marina Baia de Iguape (referida neste texto como Resex Baia de Iguape, ou simplesmente Resex), localizada no Estado da Bahia, no estuário do Rio Paraguaçu. No caso desta reserva, a interação com o rio é essencial, devido à característica de usos múltiplos às águas do rio a montante da Resex.

A governança para o uso da água tem sido uma questão tratada no Brasil já há vários anos. Nesse sentido, existe legislação para regular e equilibrar as demandas por usos múltiplos da água: abastecimento público, irrigação e energia figuram entre os principais deles. $O$ equilíbrio de interesses é tratado no âmbito das políticas públicas por meio de uma série de instrumentos, tais como os comitês de bacias hidrográficas e os planos de bacias hidrográficas; o licenciamento ambiental; e o planejamento territorial como um todo.

A Resex Baia de Iguape fica a jusante da represa que abriga a usina hidroelétrica Pedra do Cavalo. A represa foi construída originalmente visando o abastecimento público e controle de cheias e, posteriormente, foi acrescentada a geração de energia elétrica. Atualmente, os beneficiários $^{\mathrm{i}}$ da Resex experimentam uma queda na disponibilidade dos recursos explorados, principalmente crustáceos, moluscos e peixes que servem para subsistência e são também comercializados. O conflito que se estabelece envolve os municípios de Maragogipe, Cachoeira, São Félix e Saubara, entre outros.

O objetivo deste trabalho é explorar os conflitos existentes entre a gestão do uso dos recursos hídricos e a gestão da Resex Baia de Iguape. Este estudo de caso utilizou-se de documentos, tais como mapas da região e sítios de instituições e empresas envolvidas na internet; registros como relatórios públicos e de empresas, bem como a transcrição de ata de audiência pública realizada pelo Ministério Público Federal em 8 de junho de 2017 e o conjunto de apresentações, disponíveis também na internet. O trabalho se alimenta também de observação direta realizada em visita à cidade de Maragogipe e da participação em uma reunião do Conselho Deliberativo da Resex. A coleta de documentos e observação em campo documentos foram realizadas entre janeiro e junho de 2018.

\section{REFERENCIAL TEÓRICO}

A legislação brasileira estabelece o Sistema Nacional de Unidades de Conservação - SNUC. As unidades de conservação são áreas em que se restringe a possibilidade de atividades humanas, econômicas ou não, a fim de preservar certos ecossistemas e os recursos naturais. A lei estabelece duas classificações básicas para as unidades de conservação: as unidades de proteção integral, que a admitem, em princípio, apenas uso indireto de seus recursos; e as unidades de uso sustentável, que visam compatibilizar a conservação com o uso sustentável de parte dos recursos naturais (Brasil, 2000).

Um dos tipos de unidades de conservação de uso sustentável é a reserva extrativista, que segundo a lei (Brasil, 2000) é:

\footnotetext{
... uma área utilizada por populações extrativistas tradicionais, cuja subsistência baseia-se no extrativismo e, complementarmente, na agricultura de subsistência e na criação de animais de pequeno porte, e tem como objetivos básicos proteger os meios de vida e a cultura dessas populações, e assegurar o uso sustentável dos recursos naturais da unidade.
} 
A gestão das unidades de conservação em si como território e do seu entorno suscita vários conflitos devido às restrições de uso, em menor ou maior grau, conforme a regulamentação estabelece.

Sobre os conflitos ambientais, Cottey (2018), estabelece três categorias de situações conflitos: com a natureza; conflitos com outros humanos e conflitos com outros humanos e a natureza. Considera que a superação dos conflitos ambientais requer a superação da economia do tipo business-as-usual, eliminando a divisão que costuma compartimentar as questões ambientais como separadas da economia. Em relação à solução dos conflitos, considera que há dois aspectos da cultura essenciais: a cooperação e tecnologia. Por fim, considera também que a eliminação de conflitos é impossível, sempre haverá conflitos residuais. De la Cadena (2010) ressalta duas categorias antitéticas: conflitos humanos-natureza e conflitos humanos-humanos, em que, de qualquer modo, seres supostamente "superiores" determinam a extinção de seres "inferiores".

Odell et al. (2005) atribuem o aumento da frequência de conflitos sobre recursos naturais à ambiguidade da legislação, ao insuficiente conhecimento científico, à disputa jurisdicional e aos conflitos de valores dos stakeholders. Os autores também ressaltam a importância de entender as diferenças dos significados sociais, atitudes e valores na busca das soluções para os conflitos.

McShane et al. (2011) exploram as limitações das tentativas de políticas tipo ganha-ganha, em particular são céticos quanto a possibilidade de se combater a pobreza e conservar os recursos naturais ao mesmo tempo, inclusive a abordagem da Organização das Nações Unidas quanto aos Objetivos do Desenvolvimento Sustentável 2030, que tem forte base nessa visão.

Ulloa (2011) traz a possibilidade de que nativos, no caso de seus estudos os indígenas, sejam nativos ecológicos, ou seja, pessoas que protegem o meio ambiente e são a esperança para enfrentar a crise ambiental e de desenvolvimento. Ela chama atenção de que esses indivíduos são chave para elaboração de políticas, discursos, conhecimentos, representações e práticas ambientais, que ela chama de ecogovernabilidade.

Um referencial que pode ser útil para analisar os conflitos em unidades de conservação, tanto do ponto de vista interno quanto da interação com o exterior é a chamada Tragédia dos Comuns. Trata-se de uma abordagem em economia que assume que, na ausência de propriedade individual de um recurso natural livremente explorado, cada indivíduo vai buscar explorar o recurso para o seu máximo lucro individual, sem levar em conta os demais, o que fatalmente levará o recurso à exaustão. Esta teoria não levava em conta dois aspectos importantes: a multiplicidade de recursos disponíveis e a possibilidade de os exploradores se organizarem e gerar regras para conservação do recurso no longo prazo (Ostrom, 2000). A autora ressalta a existência prática e situações em que comunidades organizadas geriram a exploração dos recursos com sucesso. $\mathrm{Na}$ ausência da comunicação efetiva entre aqueles que exploram os recursos ou de uma autoridade reguladora, aí sim se torna previsível a tragédia da extinção do recurso.

Complementando essa perspectiva, este trabalho utiliza o conceito de Interesse Bem Compreendido - IBC. O IBC é um conceito derivado da interpretação de Tocqueville (1998) em seu tratado "Democracia na América". Em síntese, o IBC acontece quando existe uma busca pelo equilíbrio entre o interesse individual e o coletivo. Importante ressaltar que o IBC é um tipo ideal weberiano, ou seja, é um ideal, um norte, e não uma condição a ser alcançada de forma plena. Dessa forma, o IBC acontece quando se percebe que o interesse individual só se concretiza e se sustenta no médio e no longo prazo se o interesse coletivo também for contemplado, gerando um sistema de contrapesos entre o público (coletivo) e o privado (individual) (Cançado; Pereira; Tenório, 2015; Cançado; Villela; Sausen, 2016).

Silva (2020) realizou estudo semelhante no Comitê de Bacia Hidrográfica do Lago de Palmas - CBHLP, localizada no rio Tocantins, estado do Tocantins. Os resultados da pesquisa parecem indicar que membros desse Comitê, ao entenderem a água enquanto um Recurso de Uso Comum, percebem que ela deveria estar sujeita ao controle social (na perspectiva do Controle da Sociedade sobre as Ações do Estado). Porém, o resultado do trabalho demonstra que o Comitê, enquanto instância de decisão coletiva, que em princípio deveria ser um mediador do Interesse Bem 
Compreendido, ainda não chegou a este status devidos aos diferentes atores envolvidos. O Lago de Palmas é resultado da construção da Usina Hidrelétrica Luís Eduardo Magalhães. O CBHLP é composto por trinta e seis membros titulares e respectivos suplentes, garantido a paridade de membros e votos entre os seguimentos: Poder Público, Sociedade Civil Organizada e Usuários da Água. Um fato a ser destacado é que, dentre os usuários da água, existem empresas de grande porte que não concederam entrevistas. Foram ainda identificados conflitos diversos no CBHLP.

Entretanto, em termos efetivos de ações desempenhadas pelo referido Comitê, os dados apontados pelos respondentes indicam que este, enquanto uma instância de tomada de decisão coletiva relacionada à gestão de um recurso de uso comum, até então, não vinha desempenhando, de modo pleno (efetivo), uma Gestão sujeita ao Controle Social implementado via Gestão Social.

Argawala e Ginsberg (2017) ressaltam que há diferenças importantes entre a gestão dos recursos de propriedade comum "de fato", em que a gestão acontece com base na própria comunidade, e a gestão baseada nos aspectos, em que os atores devem cumprir uma legislação. Segundo os autores, a gestão em um regime "de fato" tem melhor impacto sobre a conservação dos recursos, no entanto é menos resiliente; enquanto a gestão baseada nos aspectos jurídicos dificulta a exclusão de agentes externos. Prost e Santos (2016) defendem a necessidade de parceria da comunidade com o Estado, não no sentido de controle territorial ou ideológico, mas sim emancipatório (Prost; Santos, 2016).

Richter e Grassman (2013) argumentam que, sob as normas e limitações do uso de recursos naturais, há a tentação de indivíduos de sob sobre explorarem os recursos a fim de aumentarem os seus lucros. Argumentam também que certos indivíduos tendem a aceitar o cumprimento das regras, na medida em que percebem que os demais também as cumprem.

\section{A RESERVA EXTRATIVISTA MARINHA BAIA DE IGUAPE E SEU CONTEXTO}

A Reserva Extrativista Marinha Baía de Iguape, localizada numa baia interna à Baia de Todos os Santos, foi criada por um decreto federal no ano de 2000 e, posteriormente, teve seus limites alterados Lei $\mathrm{n}^{\mathrm{o}} 12.058$ de 13 de outubro de 2009. É uma unidade de conservação de uso sustentável, com área constituída por praticamente todo o sistema estuarino da Baía de Iguape, da foz do Rio Paraguaçu até a Ilha de Monte Cristo, incluindo a faixa terrestre de manguezal. Está localizada nos municípios de Maragogipe e Cachoeira (BA), e com influência em municípios vizinhos como São Felix, Saubara e Salinas da Margarida, no Estado da Bahia, conforme mostra a Figura 1.

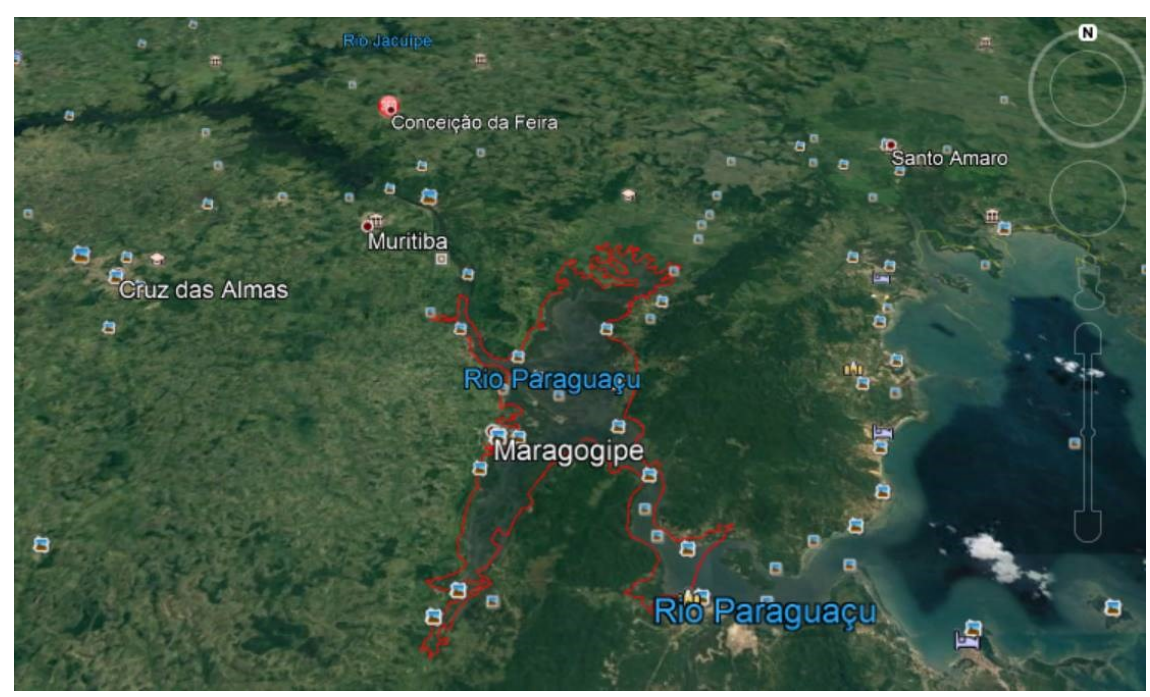

Figura 1 - Localização da Resex Marinha Baia do Iguapé (BA).

Fonte: ICMBio (2018) / Google Earth. 
A área territorial está no domínio da Mata Atlântica e a fitofisionomia predominante é o manguezal. Os principais produtos extraídos são camarões, ostras, siris, caranguejos e algumas espécies de peixes. Há também extração de piaçava e de areia em algumas comunidades específicas.

A mudança de limites da Resex, em 2009, teve como objetivo viabilizar a instalação de um estaleiro na região, seguindo política do governo federal. A empresa que se instalou é o Estaleiro Enseada do Paraguaçu, empresa voltada ao mercado de equipamentos para exploração do petróleo na camada do pré-sal, que tem em sua composição acionária um consórcio formado pela Odebrecht S.A. e pela OAS S.A., e pela japonesa Kawasaki Heavy Industries.

A Resex Baia de Iguape ocupa uma área de mais de 10.000 hectares onde fazem uso cerca de 5.000 famílias que residem nas diversas comunidades no entorno da baía. As pessoas que fazem parte dessas comunidades e que são marisqueiros, pescadores, artesãos, saveiristas, agricultores ou extrativistas vegetais que exploram os recursos artesanalmente e que moram há, pelo menos, um ano na área e tem ancestralidade nas comunidades do entorno (ICMBio, 2015) são chamados beneficiários da Reserva Extrativista. Por conta da enorme quantidade de africanos trazidos como escravos para trabalhar nas plantações de cana-de-açúcar no Recôncavo, várias dessas comunidades são remanescentes quilombolas, que se adaptaram à atividade pesqueira e que preservam aspectos importantes da cultura africana na Bahia. Estas comunidades ainda tiveram forte integração com as populações indígenas, inclusive na absorção de técnicas de pesca utilizadas pelos nativos, o que resultou em uma pesca extremamente especializada e eficiente, aumentando a pressão sobre os recursos pesqueiros.

Embora não haja ainda um plano de manejo para a Resex Baia de Iguape, que deveria haver conforme legislação vigente, trabalhos que subsidiam a gestão da unidade já foram realizados, por exemplo, a criação do Conselho Deliberativo e a elaboração de relatórios técnicos, laudos antropológicos, e plano diretivo de pesca. Esses trabalhos, com a participação da comunidade, culminaram com a elaboração do Acordo de Gestão de Pesca da Resex, em 2016. O Acordo de Gestão está em apreciação por instâncias centrais do Instituto Chico Mendes de Conservação da Biodiversidade (ICMBio), órgão responsável pela gestão de unidades de conservação federais no Brasil.

Dentre as medidas previstas na minuta do acordo em análise, estão:

a) Limites de tamanho para captura de caranguejos, siris, goiamuns, aratus, ostras, sururus e robalos;

b) Proibição de captura de fềmeas de caranguejo-uçá e goiamum o ano todo, de fêmeas ovadas de aratu e de siri;

c) Definição de malhas permitidas para redes e gaiolas para captura de várias espécies, tais como gaiolas e vários tipos de redes, bem como de comprimento de mangas de camboas;

d) Proibição de carcinicultura e permissão (para os beneficiários apenas) do cultivo de ostras;

e) Proibição de tração mecanizada para arrasto de rede, uso de explosivos ou qualquer técnica industrial;

f) Respeito a época de defeso de espécies específicas;

g) Regras para corte de mangue, uso de ilha, para navegação e extração de areia.

A reserva é administrada com a supervisão de um Conselho Deliberativo, criado pela Portaria $\mathrm{n}^{\mathrm{o}} 83$, de 15 de outubro de 2009, e que inclui representantes do Icmbio, da Capitania dos Portos, de prefeituras, de diversas comunidades locais e ainda um representante de universidade e um de empresas. Como parte de Plano Básico Ambiental estabelecido dentro do processo de licenciamento ambiental de um grande empreendimento na região, o Estaleiro Enseada do Paraguaçu - EEP, foi elaborado o Plano Diretivo de Pesca da Resex Marinha Baía do Iguape e Baixo Paraguaçu. 
A comunidade da Resex preserva diversos aspectos de identidade cultural, tais como o samba de roda, danças de origem africana e quadrilha (Dias e Bandeira, 2011). Faz parte também da realidade local uma clara divisão de tarefas, sendo algumas atividades como a mariscagem, típica de mulheres, reservando-se aos homens os trabalhos com rede para apanhar peixes (Figueiredo, 2013). Santos (2017) refere-se à existência de aspectos imateriais, particularmente afetivos e processos sociais e políticos muito ligados ao modo de vida local.

Segundo Cerqueira (2011, s.p.), a Resex Marinha Baía do Iguape é "[...] um espaço do cotidiano humano, dos moradores, dos pescadores e marisqueiras, dos viajantes etc., dos que a habitam [...]". Os autores também ressaltam a importância de se entender o território da Resex como norma, ou seja, como condicionamento do uso de aparatos e das relações sociais.

A documentação e a observação da reunião do Conselho Deliberativo mostraram uma grande tensão por causa da queda da produtividade de produtos pesqueiros da Resex Baia de Iguape.

Santana et al. (2017) constataram a contaminação de peixes com metal pesado cádmio na Baia de Iguape. Por outro lado, Freitas et al. (2017) não constataram problemas de qualidade microbiológica nas águas nas áreas de cultivo de ostras, embora expressassem uma preocupação devido ao aumento de coliformes durante períodos de maior pluviosidade e de maré de sizígia (ocasiões em que são maiores as diferenças entre maré alta e maré baixa).

Embora haja relatos de problemas, decorrentes do lançamento de efluentes de empreendimentos industriais localizados fora da Resex e de movimentos para outras atividades potencialmente impactantes como a Carcinicultura, os principais conflitos presentes no dia a dia da gestão da Resex estão relacionados à barragem Pedra do Cavalo.

Trata-se de uma barragem do rio Paraguaçu, cujo estuário é a essência da Resex Baia de Iguape. Concluída em 1975, foi construída originalmente com o objetivo primário de armazenar água para abastecimento público e secundário de controle de cheias nas cidades de São Félix e Cachoeira, com uma área alagada da ordem de $163 \mathrm{~km} 2$ (Pimentel, 2004). Posteriormente, aproveitando a barragem, foi construída a Usina Hidrelétrica Pedra do Cavalo, prevendo a instalação de duas turbinas com a potência instalada de $160 \mathrm{MW}$.

Entre os trabalhos que mostram consequências danosas da queda da vazão, estão o de Prost (2007) que já argumentava haver uma relação clara entre a fala dos pescadores e a ciência quanto aos efeitos da barragem sobre a pesca. Genz, Pereira e Lessa (2006) relataram níveis péssimos de qualidade da água, atribuindo a gestão da vazão como um dos principais fatores dessa qualidade.

Medeiros et al. (2015) relatam que as vazões médias máximas mensais a jusante da barragem caíram de um patamar que passava dos $250 \mathrm{~m} 3 / \mathrm{s}$ entre os anos de 1964 e 1978 para menos de $200 \mathrm{~m} 3 / \mathrm{s}$ entre 1986 e 2004 e para pouco mais de $50 \mathrm{~m} 3 / \mathrm{s}$ entre 2005 e 2010 . De acordo com os autores, a vazão na usina não deveria ser inferior, nos meses mais secos, a $10 \mathrm{~m} 3 / \mathrm{s}$ em média no dia. Uma das consequências da menor vazão de água doce no estuário é a ampliação da salinidade na direção do continente.

$\mathrm{Na}$ época de nossa pesquisa, a vazão liberada era de $40 \mathrm{~m} 2 / \mathrm{s}$ por períodos de aproximadamente uma hora a duas horas por dia, o que, em tese, garante uma vazão média de 3 m3/s, considerada a vazão mínima "ecológica" para manutenção do ecossistema da Resex.

Em 2009, quando venceu a licença ambiental de operação da UHE Pedra do Cavalo, a empresa deixou passar o prazo regulamentar para a solicitação da renovação da licença. O Instituto Estadual do Meio Ambiente e Recursos Hídricos - Inema, órgão estadual ambiental da Bahia, transformou então o processo de licenciamento de uma "renovação" para um novo licenciamento, com todas as etapas necessárias. Desde então, a usina vem operando sem a licença.

Até 2015, o Estaleiro Enseada do Paraguaçu (Enseada Indústria Naval AS) vinha realizando as atividades decorrentes do licenciamento ambiental, incluindo, por exemplo, atividades de educação ambiental, monitoramento do desembarque de pesca e apoio à elaboração do Plano de Manejo da Resex. 
As atividades do Estaleiro foram paralisadas em 2015, em razão das mudanças no ambiente político no Brasil. Posteriormente, a empresa obteve licença para a atividade de armazenamento temporário e distribuição de combustíveis (óleo diesel, gasolina, álcool hidratado, álcool anidro e biodiesel).

Em relação à instalação do Polo Naval (Estaleiro Enseada do Paraguaçu), Prost (2007) denunciava um desrespeito à comunidade local, configurando-se, segundo ela, uma desterritorialização econômica, política e cultural - na imobilidade - das populações tradicionais, diante da imposição da lógica global (p. 67), particularmente devido à mudança dos limites da Resex ocorrido em 2009. A autora foi seguida por Cerqueira (2011), que também previu que a população da Resex seria afetada. No entanto, talvez devido à paralisação das atividades do estaleiro, este não representava o principal conflito.

\section{PERCEPÇÕES RELATIVAS AOS IMPACTOS AMBIENTAIS E CONFLITOS PELAS DIVERSAS PARTES INTERESSADAS}

Os beneficiários da Resex percebem atualmente vários problemas relacionados à queda da vazão, ao aumento da salinidade e a, consequente, perda da biodiversidade. Veja-se o exemplo manifesto durante audiência promovida pelo Ministério Público:

[...] Ai eu pergunto como se justifica o fato de que antes da instalação da usina não havia esse nível de salinidade que se há hoje, porque se não depende da usina hidroelétrica então hoje contando com essa mesma vazão que havia antes o nível de salinidade estaria igual e a gente não percebe isso, e a gente percebe que o rio está virando mar, a água esta praticamente salobra e como já foi dita aqui várias espécies de peixes, como a pititinga, sumiu há anos desde a instalação dessa usina hidroelétrica, então eu acho que precisa de mais conhecimento sobre esses critérios de vazão ambiental.[...] (MPF, 2017, p. 64).

[...] Em Coqueiro (inaudível) do fundo um pouquinho, não tem mais jereré, quase ninguém mais pesca siri porque não tem mais. E a questão da salinidade, promotor, as pessoas iam lá, lavavam roupa, bebiam água em frente à comunidade, hoje a água é completamente salgada, se isso não é impacto ... então, o problema da salinidade do estuário é uma espécie de alga (inaudível), começou a expandir muito a proporção em uma nova macroalga, que é uma alga que é comum em praias, no estuário não dá muito por causa da salinidade, mas a salinidade é tão alta que ela se desenvolveu muito bem. São umas folhinhas verdes que parecem um coentro mesmo [...] (MPF, 2017, p. 47).

Os beneficiários observam também o fenômeno da "lama verde", que corresponde a uma alteração da cor da areia onde havia antes lama escura, que também tem diferença de consistência e dificulta a pesca, principalmente de mariscos. Além disso, os beneficiários há vários anos passaram a ser acometidos frequentemente por episódios dermatológicos de coceira intensa, de origem ainda desconhecida.

Os beneficiários enxergam a Votorantim como principal causadora de todos esses efeitos, por causa da redução da vazão. Esta visão é expressa no registro de audiência pública e, conforme o texto a seguir falado na audiência do Ministério Público, foi observada na reunião do Conselho Deliberativo.

[...] Dizer pra Votorantim que eu via muito minha avó falar e eu presenciei, o povo falando de pescado, temos a ostra, temos o sururu que hoje não encontramos mais na comunidade, eles tinham uma grande quantidade de ostra chamada de marinheira, a gente ia pra maré a partir das 7 horas e chegávamos em casa com balaio cheio de ostra marinheira, e hoje a gente não tem graças a Votorantim [...] (MPF, 2017, p.75).

Além de se queixar da Votorantim como grande causadora do fato, a comunidade também se queixa da falta de interlocução: 
[...] Porque quando o pescador chega aqui revoltado, ele está revoltado porque aquela espécie ou aquele peixe ele não achou lá, porque o jereré que ele jogou no mangue tá voltando vazio, porque o robalo não está mais sendo achado e a Votorantim tem que ter um canal de interlocução com as comunidades no entorno [...] (MPF, 2017, p.30)

Embora na comunidade haja uma divisão bem clara de trabalho entre os gêneros homens pescadores, mulheres marisqueiras (Figueiredo, 2013) - não parece haver uma percepção diferenciada em relação aos impactos ambientais, dado que há referências tanto a redução de peixes quanto de crustáceos e moluscos, com impacto, portanto, em ambos os trabalhos. Avaliam também que o Inema é conivente com a Votorantim na questão do licenciamento, aplicando uma multa vista como baixa e permitindo a operação sem licença:

[...] o Inema que faz o processo de rifa das licenças, a gente tem tranquilidade de dizer isso porque sabe que o Iguape tem 5000 famílias, por que ele licencia Pedra do Cavalo pra uma empresa que sabe que vai prejudicar 5000 famílias, que a gente sabe que se somar vai dar mais porque tem casas dessas que tem 2, 3 famílias dentro das casas. Então eu acho que o Inema é o principal rifador de licenças, digo aqui e digo em qualquer lugar. As licenças são dadas de (inaudível) e quando a gente recorre nada é feito, tem um posicionamento ridículo que se junta com o empreendedor e vem para as comunidades fazer convencimento de que o empreendimento não vai causar impacto [...] (MPF, 2017, p.70).

Há ainda algumas organizações não-governamentais atuantes que apoiam a comunidade dos beneficiários, tais como o Centro de Educação e Cultura Vale do Iguape e a Comissão Pastoral da Terra, a qual denuncia priorização do abastecimento agrícola, ex. monocultura de banana.

O ICMBio local de maneira geral apoia a comunidade local na pressão sobre a Votorantim como principal responsável pelos impactos e reconhece a necessidade de ações para restaurar, ao menos em parte, o equilíbrio da vazão de água do rio Paraguaçu para o mangue visando restabelecer sua produtividade e viabilizar o modo de vida extrativista. O exemplo, a seguir, da transcrição da audiência do Ministério Público exemplifica este posicionamento:

[...] depois pela construção da usina hidroelétrica, a partir desses atos, o fornecimento dos benefícios da maré para o pescador ficou ameaçado. Diminui o número de peixes, de mariscos, a qualidade da água e diversos outros fatores, vários manguezais desapareceram por falta de recursos, inundação, cheias e tudo mais e aí pra sobreviver, o que elas começaram a fazer? Elas começaram a diminuir a malha da rede, porque se não diminuir a malha da rede o que o pescador faz (inaudível). Então o impacto ao estuário forçou com que esses personagens começassem a usar compulsoriamente métodos menos sustentáveis para a Baía do Iguape, mas a culpa não é do pescador, é porque existem fatores externos [...] (MPF, 2017, p.54).

O ICMBio preocupa-se, ainda, com a contaminação das águas provenientes de agrotóxicos originados de agricultura a montante no Rio Paraguaçu, atividade de uma indústria de curtimento de couros que estaria lançando seus efluentes no estuário, e ainda pelas atividades do Estaleiro, que, mesmo paralisadas do ponto de vista da construção de equipamentos, têm servido de armazenamento de equipamentos antigos, o que estaria trazendo contaminantes para a baia. Por fim, tem apoiado a comunidade local na discussão com a Coordenação de Produção e Uso do ICMBio, área do órgão que precisa analisar e aprovar o Acordo de Gestão.

O Inema, como gestor dos usos múltiplos do rio Paraguaçu, argumenta que a barragem tem limitações de engenharia, citando a ausência de um dreno de fundo, a necessidade de vazão mínima de $40 \mathrm{~m} 3 / \mathrm{s}$ com ou sem geração de energia quando liberando água, e a necessidade de gerenciar o abastecimento de água. Argumenta que é uma herança de governos anteriores, que erraram ao não priorizar outras fontes de água melhores para Salvador, e que a estrutura foi construída em tempos de ditadura quando não havia discussão com a população. 
Argumenta ainda que, no processo de licenciamento da usina após 2009, o ICMBio (Instituto Chico Mendes de Conservação da Biodiversidade) teria tido uma postura ambígua, por um lado, indeferindo a licença, por outro, propondo condicionantes técnicas ao licenciamento.

Com o envolvimento do Ministério Público, o ICMBio passou a aguardar o andamento dos fatos para poder encaminhar o processo de licenciamento. Expressou que gostaria de chegar a um acordo quanto a medidas mitigadoras e compensatórias como condicionantes de licença para dar andamento ao processo.

A Votorantim argumenta que apenas opera a usina conforme as instruções de operação determinadas pela Agência Nacional de Energia Elétrica - Aneel ou pelos órgãos ambientais, conforme depoimento dos representantes durante a audiência pública: segundo ela, não poderia ser responsabilizada pelos impactos porque o contrato de concessão é construir e operar a usina conforme fornecido:

[...] O que a Votorantim faz? Ela executa essas determinações vindo ou da ONS [Operador Nacional do Sistema] ou da Aneel ou do órgão ambiental. No caso aqui, naquela época era SRH, hoje é o Inema [...] (MPF, 2017, p. 15).

Durante a audiência pública realizada em 2017 pelo Ministério Público para discussão dos conflitos entre a barragem e a Resex, o gerente de operações da Votorantim explicou que as cotas regulamentadas para operação são a mínima de 106 e a máxima de $114,5 \mathrm{~m}$ acima do nível do mar, conforme determinação das autoridades, o que leva a necessidade de se manter a vazão conforme é operada atualmente. Segundo a empresa, a água é retida na maior parte do dia porque as turbinas da usina precisam de uma vazão mínima de $40 \mathrm{~m} 3 / \mathrm{s}$ para operar, inviabilizando a manutenção de uma vazão constante de $3 \mathrm{~m} 3 / \mathrm{s}$. Além disso, a empresa argumenta que não há provas suficientes de que a baixa vazão seja a causa dos problemas constatados.

Em contrapartida, realiza vários projetos apresentados como de responsabilidade socioambiental para benefício da comunidade, tais como programas voltados à educação e ao empreendedorismo.

O Operador Nacional do Sistema - ONS, órgão responsável por manter o sistema elétrico interligado brasileiro funcionando, argumenta que recebe informações das restrições hidráulicas de cada gerador de energia e a quantidade que pode ser gerada, mas não determina restrições ou usos, e que, portanto, não determina à Votorantim a forma de ela operar.

Por fim, a comunidade reage aos argumentos de que tem a responsabilidade pelos impactos devido a sobrepesca e ao uso de apetrechos inadequados:

[...] A própria empresa contrata outras empresas pra fazer estudos e vem com esse resultado pra gente, dizendo que não causou impacto algum, é por causa do esgoto doméstico é por causa dos pescadores que pescam de malha fina, é por isso e por aquilo, mas a gente, que é pescador e marisqueira, sabe que isso não é real [...] (MPF, 2017, p.8)

\section{DISCUSSÃO}

O primeiro conflito a se analisar é o conflito de uso do recurso hídrico. A intervenção passada no curso do rio Paraguaçu acentuou a divisão existente entre a bacia hidrográfica e a região estuarina em que se localiza a Resex. Esta divisão é de natureza ambiental, na medida em que limita o acesso da região estuarina ao recurso hídrico e causa um impacto na vazão hídrica, na salinidade e, portanto, na dinâmica desse ecossistema afetando a dinâmica de carreamento de sólidos, primariamente na salinidade do estuário, o que leva a mudança nos padrões de disponibilidade de pescado. O impacto causado leva a conflitos entre humanos dentro da própria Resex.

Dada a existência dos impactos, há um segundo conflito que é o da responsabilização pela origem. Aí notam-se duas vertentes: a primeira, relativa à incerteza científica da causa do declínio do pescado - seria pela alteração do regime de vazões, como dizem os pescadores e marisqueiras, 
ou pelo uso de apetrechos inadequados, como diz a Votorantim? A segunda vertente, é a responsabilização pelas tomadas de decisão sobre a variação da vazão na barragem. A Votorantim argumenta que não é ela que toma as decisões, apenas as cumpre, mas a comunidade não reconhece a legitimidade deste argumento. Ao mesmo tempo, parte da comunidade não reconhece as ações voltadas para desenvolvimento comunitário da Votorantim, uma vez que são envolvidas pessoas específicas e não as comunidades.

Embora o acordo de gestão da pesca tenha sido construído buscando a participação da comunidade, parece haver resistência de dois tipos. O primeiro é formal e relacionado à necessidade de adaptação dos apetrechos de pesca para atender às regras propostas. O segundo se refere à tensão para atendimento de necessidades imediatas da comunidade por alimento, o que pode levar à sobrepesca ou captura de indivíduos fora dos padrões estabelecidos no Acordo de Gestão.

Ambas os aspectos desembocam em conflitos políticos em que cada parte busca minimizar sua responsabilidade pela situação, e, portanto, não se dispõe a abrir mão de parte de seus interesses visando solucionar a situação.

\subsection{A gestão dos recursos hídricos}

O primeiro aspecto a se discutir é a presença dos interesses no gerenciamento dos recursos hídricos. Por um lado, há duas instituições que cuidam de interesses coletivos daqueles que são representados nelas: o Comitê de Bacia Hidrográfica e o Conselho Deliberativo da Resex. Entre eles está a Votorantim, operadora da barragem e da usina hidroelétrica, conforme mostra a Figura 2. Há ainda a interferência indireta do Operador Nacional do Sistema, que também tem interesse nesse contexto, mas que declara que apenas recebe informações.

Cada um desses atores tem seus próprios interesses, que pouco parecem ter em comum, e, principalmente, a Votorantim acaba agindo pautada pelos seus contratos individuais com cada um dos lados, e não com base num interesse coletivo.

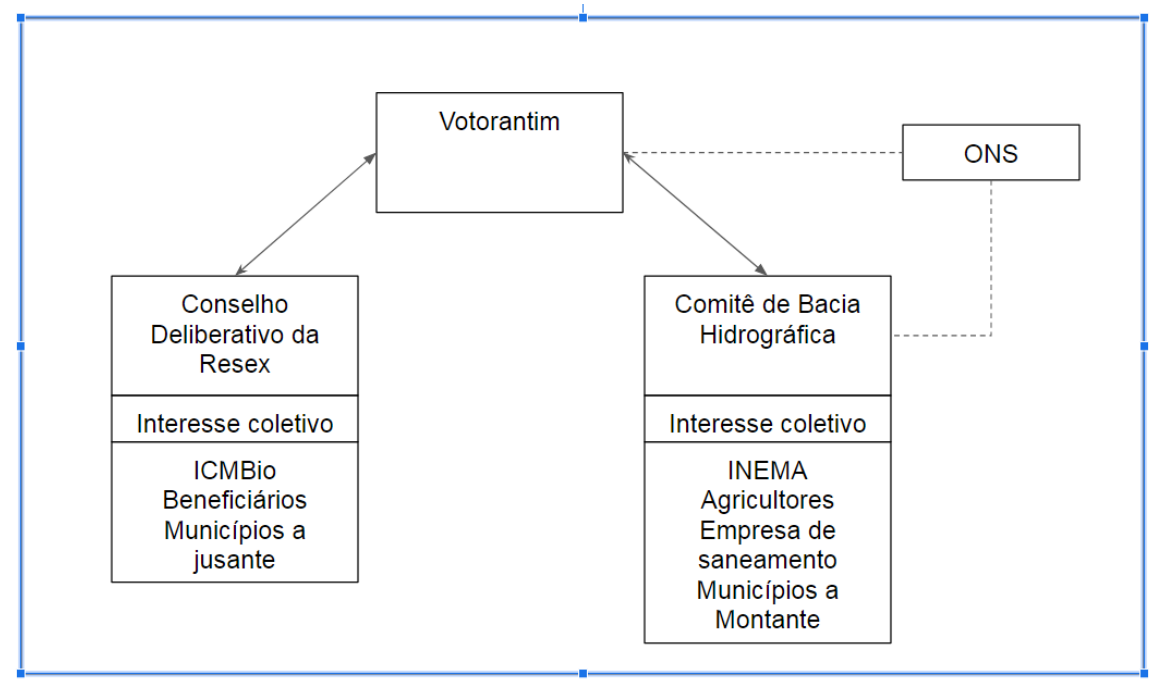

Figura 2. Diagrama esquemático dos interesses envolvidos na gestão da Resex

Fonte: Os autores

Do ponto de vista da legislação de recursos hídricos, está na lei que deve haver priorização do abastecimento potável e de dessedentação de animais em situações de escassez (Brasil, 1997), o que justificaria a retirada de água do rio Paraguaçu no volume que se fizer necessário para essas necessidades. Por outro lado, as diretrizes gerais da lei embora preconizem a integração da gestão das bacias hidrográficas com a dos sistemas estuarinos, faz com que estes sejam vistos como elementos externos à bacia ("integrado com", e não "como parte integrante de") fazendo com que, em situações de conflito, os gestores e atores sociais envolvidos na bacia hidrográfica acima do 
estuário deem preferência aos seus interesses. Isso confirma a visão de Odell et al. (2005) de que a legislação ambígua é uma das fontes dos conflitos socioambientais em unidades de conservação. Nesse sentido, seria importante haver uma articulação mais efetiva entre a comunidade da Resex e o Comitê de Bacia Hidrográfica, de algum modo superando a separação induzida pela legislação. Isso estaria alinhado com a ideia de Cottey (2018) de que a cooperação faz parte da superação dos conflitos ambientais. No entanto, não se nota no contexto uma abordagem ganha-ganha, conforme proposto por McShane et al 2011). Aparentemente, o conflito sobrevive a um jogo em que, necessariamente, se um lado ganha, o outro perde.

Nessa questão, observa-se a importância dos envolvidos em compreender a questão do IBC, o que não parece ocorrer no contexto estudado. Ao priorizar seus interesses, não considerando os interesses coletivos, gera-se um conflito socioambiental com potencial de judicialização e prejuízos para todas as partes envolvidas. Essa tensão gerada pode extrapolar a perspectiva local, se forem consideradas as questões relativas à desterritorialização (tanto em relação ao território em si, quanto ao modo de vida ancestral adotado) de populações quilombolas. Os discursos confirmam a observação de Santos (2017) e de Dias e Bandeira (2011) sobre a importância dos aspectos imateriais e culturais da vida local, bastante valorizados pelos beneficiários mais antigos.

No entanto, há uma dificuldade em se localizar os interesses comuns de atores tão distantes quanto os beneficiários da Resex, os agricultores da região de montante e a população urbana de Salvador e Feira de Santana.

A Votorantim tem tentado diminuir a tensão apoiando projetos sociais na comunidade. Embora promova benefícios, por exemplo em projetos educacionais, a parcela mais mobilizada dos beneficiários entende isso como um estratagema para tergiversar, e expressa a opinião de que isso não contribui para a solução do conflito.

Do ponto de vista da engenharia, existem soluções possíveis, já estudadas e mesmo implantadas por outras hidroelétricas, conforme alerta um técnico do ICMBio durante a audiência pública:

[...] Outras hidroelétricas que fizeram operativas técnicas de alteração de motorização, botar turbinas menores, fazer sub-barragens para regulação de vazão. Enfim, outras hidroelétricas fizeram estudos técnicos [...] (MPF, 2017, p. 60).

Este aspecto traz à tona novamente Cottey (2018), que atribui à tecnologia o papel de uma aliada importante para superação dos conflitos ambientais. A falta de acesso a esta tecnologia, alegadamente por falta de recursos financeiros, acaba sendo um óbice à resolução do conflito. Do ponto de vista formal e legal, talvez a geração de energia elétrica devesse ser interrompida, uma vez que a usina não tem mais uma licença ambiental para operar. Obviamente isso traz questões importantes a respeito do aproveitamento do potencial energético e sobre quem pagaria pelas reformas necessárias, dado que a usina não é de propriedade da Votorantim, mas sim propriedade pública concedida.

Evidentemente a solução de parar de gerar energia para melhorar a vazão não parece estar no horizonte da Votorantim, embora para o ONS aparentemente isso não seja um problema. Seria necessário estudar um mais a fundo as regras de concessão. Por outro lado, a Votorantim argumenta que não há, fisicamente, como trabalhar com uma vazão abaixo de $40 \mathrm{~m} 3 / \mathrm{s} \mathrm{mesmo} \mathrm{sem} \mathrm{gerar}$ energia, dadas as características de engenharia dos mecanismos envolvidos.

Em que pese a importância da determinação de uma vazão "ecológica" mínima para manutenção do mangue e seus recursos, seja pelo método já usado para definir os $3 \mathrm{~m} 3 / \mathrm{s}$, há outra dificuldade que se sobrepõe. A questão da diferença entre os valores dos stakeholders (Odell et al., 2005) aparece claramente quando os beneficiários partem do princípio de que vale a pena manter o seu modo de vida, enquanto outros partem do princípio de que é um estilo de vida, carregado de aspectos culturais (Dias e Bandeira., 2011; Santos, 2017) que não vale mais a pena, e que a geração de empregos industriais e a garantia de água para irrigação e energia elétrica têm prioridade sobre 
isso. É uma questão de valores que supera qualquer realidade científica. O conflito territorial surge, num momento, do conflito de normas, e, em seguida do conflito de valores, esses que deveriam ser a base para solucionar uma questão que a norma formal não resolve. O território como norma (Cerqueira, 2011) se torna então o próprio conflito.

Do ponto de vista da tragédia dos comuns, há duas situações a analisar: a exploração dos recursos pesqueiros e a exploração da água. No caso dos recursos pesqueiros em si, numa situação em que o ecossistema manguezal esteja saudável, há uma estrutura comunitária e formal que permitiria uma exploração sustentável: as comunidades são organizadas, há um conselho gestor, há regras propostas com as limitações de captura visando manter as populações de peixes, mariscos e crustáceos, favorecendo a visão alternativa da tragédia dos comuns apontada por Ostrom (2000). No entanto, esse contexto é afetado pela questão do uso da água.

No caso do uso da água, predomina a existência de legislação ambiental - licenciamento, áreas protegidas, gestão de usos múltiplos de recursos hídricos - que parece fazer a decisão ficar no âmbito da gestão "jurídica". Essa leva a entender a Resex como algo externo à bacia hidrográfica, e a bacia hidrográfica como externo à Resex. A falta de comunicação clara entre os regulamentos que regem cada um desses territórios, e a falta de articulação entre os agentes de cada um desses territórios, acaba por confirmar a primeira versão, causando então a diminuição drástica não só do recurso água para um dos territórios, mas também do recurso pesqueiro. Esta cisão leva a uma tensão que Prost (2007) caracterizou com desrespeito às comunidades no caso do polo Naval, e que ao que tudo indica permanece no caso da barragem Pedra do Cavalo, ou, ao menos, a comunidade se manifesta desta forma.

Complementando o argumento, a solução do conflito parece distante. Parece razoável argumentar que as partes envolvidas poderiam chegar a um acordo (considerando os limites da legislação) baseando-se no equilíbrio de interesses (IBC), evitando perdas de diversas naturezas: imagem (nacional e internacional incluídas), financeiras (ambos os lados), culturais (quilombolas), dentre outras. Se perceber como parte de um processo e não dono dele, é questão crucial para a solução de conflitos que envolvem recursos naturais e a própria vida em sociedade. Dessa forma, a proposta é, por meio do IBC, minimizar os efeitos da Tragédia dos Comuns.

Pode parecer utópico o argumento, e talvez o seja, tendo em vista o histórico envolvido e os prováveis recursos financeiros que uma solução técnica poderia requerer. Porém, a questão central a ser considerada é que existem "visões de mundo" diferentes e a maneira pela qual elas podem conviver parte do reconhecimento da posição do outro no processo, passando pela capacidade de ouvir e discutir, para que, ao final, uma solução intermediária seja encontrada. Essa solução não será ótima para nenhuma das partes, se considerar apenas o interesse individual/privado, mas tem o potencial de ser uma solução possível, considerando o equilíbrio de interesses.

$\mathrm{Na}$ discussão dos conflitos ambientais, surgem ainda como temas questões relacionadas à qualidade da água, tais como uma manifestação de "coceira" que ocorre em certos locais e certas épocas nas pessoas que entram na água para pescar, bem como a presença de poluição por matéria orgânica (Freitas et al, 2017) e industrial (Santana et al, 2017). Esses aspectos, embora presentes com menor intensidade, contribuem para que o problema precise ser tratado como multicausal, e dá oportunidade para os argumentos da Votorantim de trazer incerteza científica à hipótese de que a restrição da vazão é a maior causadora dos problemas, em contraposição a diversos estudos com os de Prost (2007) e de Genz et al (2006) que atribuem ao controle da vazão a perda de qualidade da água, o aumento da salinidade e dos consequentes impactos.

\subsection{Sobre os métodos de pesca}

Outro conflito, que parece menos evidente, refere-se ao uso de apetrechos de pesca apropriados e do respeito a regras como tamanhos e épocas do pescado. Esses parâmetros não foram ainda formalmente aprovados nas instâncias superiores do ICMBio, no entanto o Conselho Deliberativo da Resex está mobilizado para sua implantação. Tal implantação tem dois aspectos: 
um deles é a substituição dos apetrechos de pesca, como redes e gaiolas, aos tamanhos prescritos no acordo; o segundo é a adesão da comunidade aos comportamentos acordados, tais como soltar as fêmeas ovadas de siris, respeitar os defesos, as quantidades de gaiolas e locais de pesca.

Do ponto de vista formal, o Acordo de Gestão de Pesca foi construído buscando ser participativo e envolvendo as comunidades. No entanto, grande parte da comunidade ainda usava os métodos que não aderiam às regras propostas, tais como tamanhos mínimos de malhas de redes e gaiolas, e de pescados. Dois argumentos principais se apresentaram em reunião do Conselho Deliberativo: o primeiro, de que o aumento das malas para limitar a captura a indivíduos maiores inviabilizava a atividade pela falta disponibilidade de pescado (peixes, crustáceos e mariscos) no ambiente; o segundo, a falta de recursos próprios para aquisição dos novos apetrechos.

A presença de outros métodos não aceitos, tais como pesca com bombas, também era relatada durante reuniões do Conselho Gestor da Resex. Nesse contexto, parece haver um senso de proteção da própria comunidade, e não surgiam acusações a nomes específicos, mas apenas a menção genérica a tais práticas. Nesse caso, faz parecer que não há interesse num conflito homemnatureza, mas sim homem-homem (Cottey, 2018; Cadena, 2010).

A solução de elaborar um acordo de gestão de pesca de modo participativo, a princípio, buscou princípios de cooperação (Cottey, 2018), no entanto a falta de acesso às tecnologias necessárias (Cottey, 2018) dificulta a superação do conflito, e a comunidade permanece na espera de uma cooperação externa por meio de recursos financeiros ou de aporte direto de novos apetrechos por instituições externas. Não ocorrendo essa cooperação, o conflito não se supera. Dentro da própria comunidade, como sistema fechado, faria sentido analisar o conflito com base na tragédia dos comuns. No entanto, a expressão dos beneficiários é de que o impacto já é tão sensível que as normas planejadas não dão conta de garantir a manutenção dos recursos naturais e a sobrevivência da comunidade. Não parece haver solução sem que exista uma interação cooperativa com sistemas externos.

\subsection{Sobre a tragédia dos comuns e o interesse bem compreendido}

É importante ressaltar que há três contextos a serem considerados:

a) a Bacia Hidrográfica do Rio Paraguaçu, em que o recurso compartilhado é a água, e tem uma gestão institucional e formal que a enxerga como um sistema praticamente fechado, trocando apenas informações com o sistema estuarino;

b) a reserva extrativista em si, em que os recursos compartilhados são os recursos pesqueiros, e que também tem uma gestão institucional e formal que a enxerga com um sistema praticamente fechado, voltado às pessoas que ali convivem;

c) o contexto de interação entre os dois sistemas, em que a governança do sistema mais prejudicado (a reserva extrativista) busca interagir com o sistema externo para resolver seus problemas, ao mesmo tempo em que a governança do sistema que não é afetado pelo outro (a bacia hidrográfica) resiste a responder de maneira positiva ou propositiva. $\mathrm{O}$ conflito entre a economia business as usual, que considera o impacto sobre a Resex quase que como inevitável, e a luta da comunidade para sobreviver mantendo seu modo de vida, acaba por não ser superado num acordo que equilibre os interesses, na perspectiva do Interesse Bem Compreendido. Parece que a falta de reconhecimento da legitimidade dos vários interesses acaba por se sobrepor às alternativas tecnológicas e institucionais existentes.

Do ponto de vista da Tragédia dos Comuns, o conflito dos recursos hídricos parece uma situação em que os entes envolvidos teoricamente estariam sujeitos a regras legais e de convivência que possibilitariam a perpetuação dos recursos. No entanto, parece haver dois entraves: o primeiro legal, pela exclusão da zona estuarina da gestão dos recursos hídricos, e o outro uma distância entre os beneficiados pela redução da vazão, que são agricultores a montante e as cidades de Salvador, 
Feira de Santana e região, abastecidas pela água do Rio Paraguaçu. Esses entraves parecem ser de estabelecimento claro de um sistema fechado, no sentido estabelecido por Bertalanffy (1975), sem troca de matéria, energia ou informação com entes externos. O sistema fechado parece ser um pressuposto implícito pouco discutido da teoria trabalhada por Ostrom e Hardin. De fato, as ideias originais de Hardin sobre a tragédia dos comuns foram orientadas pela teoria geral dos sistemas (Oakes, 2016). Oakes ainda critica o fato de que as ciências dos sistemas racionalizavam muito em termos de coordenação entre partes e o todo, mas nem sempre acertavam ao desmontar o todo em partes (2016). De qualquer modo, é preciso que haja um limite claramente fechado para o sistema estudado.

Em outro contexto, o das práticas de pesca dentro da comunidade, parece ser mais evidente a abordagem da tragédia dos comuns, dado que o limite do sistema é mais claramente definido: do ponto de vista geográfico, as áreas de pesca; do ponto de vista das pessoas, as comunidades pesqueiras. No entanto, a solução parece ainda depender de recursos externos, dado que a comunidade argumenta que não tem dinheiro para adquirir novas redes, gaiolas e demais apetrechos. Houve uma tentativa por parte do ICMBio de obter doações de gaiolas novas para captura de siris, com tamanho apropriado, mas não estavam obtendo sucesso.

Seria importante, no entanto, uma aproximação da comunidade para se compreender se há outros fatores envolvidos - por exemplo a pesca de indivíduos menores tem alguma vantagem operacional? O fato de ser uma comunidade carente e impactada tem trazido benefícios assistenciais atraentes?

As questões relativas à lógica dos resultados atingidos por populações vulneráveis, como é o caso, necessitam de mediação e transferência de tecnologia para tornar viável (econômica, social e ambientalmente) o trabalho realizado. $\mathrm{O}$ aumento da renda e a melhora das condições de trabalho podem contribuir para a construção do Interesse Bem Compreendido, na medida em que se tem as bases de sustento da comunidade melhoradas.

Do ponto de vista da ecogovernabilidade de Ulloa (2011), parece ficar claro que a comunidade pode ser composta de nativos ecológicos e de não-nativos ecológicos, dado que há pessoas que não se colocam como fonte de solução para práticas que auxiliem a melhoria da gestão da Resex.

\section{CONSIDERAÇÕES FINAIS}

A situação como um todo parece ter uma multiplicidade de origens: falhas na engenharia da barragem e da usina; sobre explotação da água a montante, agravada pela sequência de anos com menor pluviosidade e, portanto, menor disponibilidade hídrica total; falhas na estrutura de governança, tanto do ponto de vista da legislação e da estrutura formal, quanto da conjuntura do processo decisório. Esta multicausalidade permite que as narrativas de cada ator envolvido sejam consideradas apenas como percepções, e não como dados objetivos de realidade com validade científica.

Em que pese a potencial presença de outros fatores, a maioria dos estudos técnico-científicos e as mudanças na população de fauna aquática deixam claro que, neste contexto multicausal, a gestão da vazão da barragem desempenha um papel preponderante, estando associada à mudança na salinidade e consequentes mudanças na fauna aquática.

O sistema de gestão de recursos hídricos não tem dado conta de resolver os conflitos, apontando para a necessidade de revisão, de modo a não separar a gestão da unidade de conservação da gestão da bacia hidrográfica, pois neste modelo os objetivos são conflitantes. É preciso encontrar formas para se superar a visão da bacia hidrográfica como sistema fechado, ou então ampliar o escopo das bacias hidrográficas para incluir as regiões estuarinas. Esta cisão parece produzir visões parciais pelos vários agentes. A superação desta cisão pode abrir caminho que leve ao Interesse Bem Compreendido, e pôr fim a uma solução de consenso que possa atender às 
necessidades tanto da economia business as usual da operação da barragem, quanto dos aspectos sociais e imateriais da comunidade de beneficiários.

Cabe ressaltar que o sistema judiciário também responde de maneira bastante lenta, trazendo o risco de criar uma degradação de longo prazo com consequências insuperáveis para a comunidade. Permanece a dificuldade de linguagens, ou seja, em valorar os serviços ambientais não apenas em termos do PIB gerado para os beneficiários, mas também do valor cultural da preservação do modo de vida e do valor ecológico da área.

Ao mesmo tempo, é importante entender a dinâmica da variação de espécies e a produtividade da Reserva para entender como explorar as mudanças, que podem ser inevitáveis do ponto de vista político, ou mesmo do ponto de vista das mudanças climáticas, a fim de se estabelecer modos de produção apropriados à comunidade e ao seu modo de vida.

O estudo do contexto da Reserva Extrativista Marinha Baia de Iguape precisa ser aprofundado para conhecer melhor as potencialidades da própria comunidade em superar as dificuldades trazidas pelos conflitos de governança, visando a um tempo adaptar-se à nova realidade ambiental permitindo sua sobrevivência, e ao mesmo tempo valorizando seu modo de vida e conhecimento tradicionais. Seria importante também conhecer as diferentes posturas dentro da própria comunidade, possivelmente diferenças intergeracionais, questões de gênero ou entre as várias comunidades no entorno da Resex. Algumas possibilidades, tais como monitoramento participativo e desenvolvimento e aprimoramento do processamento de pescado e da cadeia de suprimentos, poderiam contribuir para isso. Tais condições que podem contribuir para o equilíbrio de interesses no caminho da construção do Interesse Bem Compreendido.

Este trabalho traz como contribuição empírica importante a indicação de que a fundamentação legal da gestão de recursos hídricos no Brasil desempenha um papel importante na origem dos conflitos ao deixar a zona estuarina de fora da gestão da bacia hidrográfica. Por outro lado, parece haver também uma resistência dentro da própria comunidade em estudar o seu próprio papel na promoção de ações de gestão, para ir além de cobrar ações das autoridades.

Do ponto de vista teórico, este trabalho mostra possibilidades e limitações da abordagem a partir da tragédia dos comuns, e da importância em se aprofundar o entendimento das relações entre grupos envolvidos do ponto de vista do interesse bem compreendido como base para a ação política na gestão de recursos escassos.

\section{REFERÊNCIAS}

Bertalanffy, L. v. (1975). Teoria geral dos sistemas. Petrópolis: Vozes. Editora Vozes; (8 edição) (1 janeiro 2014)

Brasil. (1997). Lei 9.433, de 8 de janeiro de 1997. Recuperado em 17 junh.2021, de: http://www.planalto.gov.br/ccivil_03/leis/19433.htm.

Brasil. (2000). Lei no 9.985, de 18 de julho de 2000. Disponível em: http://www.planalto.gov.br/ccivil_03/leis/19985.htm. Acesso em 17 Jun 2021.

Cançado, A. C., Pereira, J. R., \& Tenório, F. G. (2015). Gestão social: epistemologia de um paradigma. Curitiba: CRV. (2a . Edição).

Cançado, A. C., Villela, L. E., \& Sausen, J. O. (2016). Gestão social e gestão estratégica: reflexões sobre as diferenças e aproximações de conceitos. Environmental \& Social Management Journal/Revista de Gestão Social e Ambiental, 10(3).

Cerqueira, I. L. S. (2011). Território e norma: a implantação do pólo naval na Resex Marinha Baía do Iguape. Seminários Espaços Costeiros, 1. 
Cottey, A. (2018). Environment change, economy change and reducing conflict at source. Ai \& Society, 33(2), 215-228.

Dias, T.L.S; Bandeira, F.P.S.F. (2011) Etnoecologia na Baía do Iguape: identidade cultural, territorial e conflitos socioambientais em comunidades tradicionais. In: Seminário de Iniciação Científica, 15. UEFS, Feira de Santana, BA. p. 188-191.

Enseada Indústria Naval S.A. (2018) Enseada obtém licença para implantar terminal de líquidos e granéis. Recuperado em 17 jun.2021, de:

http://www.navegandojuntos.com.br/comunicacao/enseada-obtem-licenca-para-implantar-terminalde-liquidos-e-graneis/.

Figueiredo, M. M. (2013). A participação da mulher na organização socioespacial de comunidades pesqueiras: Um estudo de caso na Reserva extrativista Baía do Iguape. Revista Latino-Americana de Geografia e Gênero, 4(2), 77-85.

Freitas, F., Neiva, G. S., Cruz, E. S. D., Santana, J. D. M., Silva, I. D. M. M. D., \& Mendonça, F. D. S. (2017). Qualidade microbiológica e fatores ambientais de áreas estuarinas da Reserva Extrativista Marinha Baía do Iguape (Bahia) destinadas ao cultivo de ostras nativas. Engenharia Sanitária e Ambiental, 22(4), 723-729.

Genz, F.; Pereira, M. A. G.; Lessa, G. C. (2006) Avaliação dos efeitos da Barragem de Pedra do Cavalo sobre a circulação estuarina do Rio Paraguaçu e Baía de Iguape. Congresso Brasileiro de Química, 56.

ICMBio - Instituto Chico Mendes de Conservação da Biodiversidade. Portaria N. 47 de 6 de Outubro de 2015. Diário Oficial da União, Seção 1. 7 de outubro de 2015. p. 49.

ICMBio - Instituto Chico Mendes de Conservação da Biodiversidade. Resex Marinha da Baia do Iguape. Recuperado em: 18 mai.2018, de:

http://www.icmbio.gov.br/portal/unidadesdeconservacao/biomas-brasileiros/marinho/unidadesdeconservacao-marinho/2229-RESEX-baia-de-iguape.

ICMBio - Instituto Chico Mendes de Conservação da biodiversidade. Minuta do Acordo de Gestão de Pesca da Reserva Extrativista Marinha Baia de Iguape. [Processo $n^{0}$ 02188.000009/2015-90]

McShane, T. O., Hirsch, P. D., Trung, T. C., Songorwa, A. N., Kinzig, A., Monteferri, B., ... \& Welch-Devine, M. (2011). Hard choices: making trade-offs between biodiversity conservation and human well-being. Biological Conservation, 144(3), 966-972.

Medeiros, Y. D. P., Fontes, A. S., \& Castro, M. Q. (2015). Plano de operação de reservatórios para atendimento aos requerimentos da vazão ambiental. Comitê brasileiro de barragens, seminário nacional de grandes barragens Foz do Iguaçu-PR, 30.

MPF - Ministério Público Federal (2017). Ata da audiência pública: a Usina Hidrelétrica Pedra do cavalo e seus impactos ambientais na Resex Baía do Iguape. Recuperado em 17 junh.2021, de: https://cdn.jornalgrandebahia.com.br/2017/06/Ata-da-audi\%C3\%AAncia-p\%C3\%BAblicasobre-a-Usina-de-Pedra-do-Cavalo.pdf.

Oakes, J. (2016). Garrett Hardin's Tragic Sense of Life. Endeavour, 40(4), 238-247.

Odell, J., Mather, M. E., \& Muth, R. M. (2005). A biosocial approach for analyzing environmental conflicts: a case study of horseshoe crab allocation. Bioscience, 55(9), 735-748.

Ostrom, E. (2000). Reformulating the commons. Swiss Political Science Review, 6(1), 29-52. 
Pimentel, V. (2004). Alternativas de solução para os impactos físicos de barragens,

416f (Dissertação, Mestrado em Engenharia) - Escola Politécnica da Universidade de São Paulo, São Paulo.

Prost, C. (2007). Efeitos da barragem Pedra do Cavalo sobre a pesca artesanal na baía do Iguape. Encontro Brasileiro de Ciências Sociais sobre Barragens, 2. Recuperado em 17 jun, 2021, de:

https://www.researchgate.net/publication/317318661_Efeitos_da_barragem_da_Pedra_do_Cavalo_ sobre_a_pesca_artesanal_na_baia_do_Iguape.

Prost, C., \& Santos, M. A. (2016). Gestão territorial em unidades de conservação de uso sustentável e incoerências no SnUC. Novos Cadernos Naea, 19(1).

Santana, C. O., Jesus, T. B., Aguiar, W. M., Franca, W. D. J. S. A., \& Soares, C. A. C. (2017).

Assessment of health risk related to the ingestion of trace metals through fish consumption in Todos os Santos Bay. Environmental monitoring and assessment, 189(5), 204.

Silva, F. R. (2020) Gestão social e controle social das águas: o caso do Comitê de Bacia

Hidrográfica do Lago de Palmas. 2020, 315 f. Tese (Doutorado), Programa de Pós-Graduação em Desenvolvimento Regional da Universidade Federal do Tocantins - Ppgdr-UFT, Palmas.

Tocqueville, A. (1998). Democracia na América. (Trad. José Lívio Dantas). Rio de Janeiro: Biblioteca do Exército.

Ulloa, A. (2011). A ecogovernamentalidade e suas contradições. Ecopolítica, (1)

\section{Nota:}

Projeto financiado pelo Conselho Nacional de Desenvolvimento Científico e Tecnológico - CNPq e ao Instituto Chico Mendes de Conservação da Biodiversidade - ICMBIO, processo CNPq $421450 / 2017-7$.

RGSA adota a Licença de Atribuição CC BY do Creative Commons (https://creativecommons.org/licenses/by/4.0/).

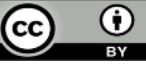

i O termo "beneficiários" é aqui utilizado como jargão da gestão de reservas extrativistas. Refere-se a pessoas que vivem no entorno da reserva e que sobrevivem, ao menos em parte, explorando legalmente seus recursos naturais. 